Tropical Journal of Pharmaceutical Research October 2017; 16 (10): 2515-2520

ISSN: $1596-5996$ (print); 1596-9827 (electronic)

(C) Pharmacotherapy Group, Faculty of Pharmacy, University of Benin, Benin City, 300001 Nigeria.

All rights reserved.

Available online at http://www.tjpr.org

Original Research Article

http://dx.doi.org/10.4314/tjpr.v16i10.27

\title{
Effect of moxifloxacin on oxidative stress, paraoxonase-1 (PON1) activity and efficacy of treatment in patients with multiple drug-resistant tuberculosis
}

\author{
Hongguo Yang ${ }^{1}$, Yanyan Zhao ${ }^{1}$, Yunbo $\mathrm{Ma}^{2}$, Qiang Wen ${ }^{3 \star}$ and Minghui Zhang ${ }^{4}$ \\ ${ }^{1}$ Department of Clinical Laboratory, ${ }^{2}$ Department of Tuberculosis Prevention, ${ }^{3}$ The Third Department of Internal Medicine, \\ ${ }^{4}$ Department of Radiology, Eastern Medical District of Linyi People's Hospital, Linyi City, Shandong Province 276034, China \\ *For correspondence: Email: qiangwenly@163.com
}

Sent for review: 27 June 2017

Revised accepted: 25 September 2017

\begin{abstract}
Purpose: To investigate the effect of moxifloxacin on paraoxonase-1 (PON1) activity, and serum oxidative stress in patients with multiple drug-resistant tuberculosis (MDR-TB).

Methods: A total ofof 130 MDR-TB patients who were treated with moxifloxacin from October 2014 to October 2010 in Eastern Medical District of Linyi People's Hospital of Shandong Province, China were randomly divided into an observation group (65 cases, moxifloxacin group) and control group (65 cases, non-moxifloxacin group). Total oxidant status (TOS), total antioxidant status (TAS), oxidative stress index (OSI), PON1 levels and treatment efficacy for groups were determined.

Results: Compared with pre-treatment levels, TOS $\left(23.3 \pm 4.7 \mathrm{vs} 13.9 \pm 3.3\right.$ umol $\mathrm{H}_{2} \mathrm{O}_{2} \mathrm{Eq} / \mathrm{L}, t=13.20$, $p=0.00)$ and $\mathrm{OSI}(17.4 \pm 4.8$ vs $5.7 \pm 1.4 \mathrm{U}, t=18.87, p=0.00)$ of the observation group significantly decreased, while TAS (1.4 \pm 0.5 vs $3.5 \pm 0.7$ umol Trolox $E q / L, t=19.68, p=0.00)$ and PON1 (15.5 \pm 6.9 vs $31.1 \pm 8.3 \mathrm{U} / \mathrm{L}, t=11.65, p=0.00)$ significantly increased. TOS $(23.3 \pm 4.7 \mathrm{vs} 13.9 \pm 3.3 \mathrm{umol}$ $\left.\mathrm{H}_{2} \mathrm{O}_{2} \mathrm{Eq} / \mathrm{L}, t=7.73, p<0.05\right)$ and OSI $(16.9 \pm 5.5$ vs $7.4 \pm 3.2 \mathrm{U}, t=12.04, p=0.05)$ reduced significantly in the control group. Moxifloxacin correlated positively with $\triangle T A S(r=0.697, p=0.04)$ and $\triangle P O N 1(r=0.785, p=0.01)$, but correlation with $\triangle T O S(r=-0.625, p=0.01)$ was negative. Efficacy was significantly higher in the observation group than that in the control group $(81.54 \%$ vs $56.92 \%, p=$ 0.00).

Conclusion: Oxidative stress injury in MDR-TB patients may be effectively managed by combination of moxifloxacin with anti-TB treatment
\end{abstract}

Keywords: Multiple drug-resistant TB, Moxifloxacin, Paraoxonase, Oxidative stress

\begin{abstract}
Tropical Journal of Pharmaceutical Research is indexed by Science Citation Index (SciSearch), Scopus, International Pharmaceutical Abstract, Chemical Abstracts, Embase, Index Copernicus, EBSCO, African Index Medicus, JournalSeek, Journal Citation Reports/Science Edition, Directory of Open Access Journals (DOAJ), African Journal Online, Bioline International, Open-J-Gate and Pharmacy Abstracts
\end{abstract}

\section{INTRODUCTION}

Tuberculosis (TB) is one of the global public health problems. In recent years, with greater attention paid to TB prevention and treatment technology, the incidence of TB has declined. However, there are still a large population of patients with TB $[1,2]$. China ranks second in the world, with respect to the number of TB patients [3]. Due to irregularities in availability of appropriate clinical medications and variations in the causative organism, Mycobacterium tuberculosis, the incidence of drug resistance is gradually increasing. Multiple drug-resistant TB (MDR-TB) is that patients have a resistant to two or more anti-TB drugs, such as the conventional first-line anti-TB drugs rifampicin and isoniazid.

Drug resistance greatly increases the treatment cycle and adverse reactions, resulting in a 
significant reduction in cure rate [4]. Relevant epidemiological studies have shown that total resistance in TB has reached up to $37.62 \%$ [5]. Results of assessment by World Health Organization showed that the incidence of MDRTB in TB patients was $20 \%$. This is a great challenge to clinical treatment of TB because it seriously affects the quality of life and prognosis [6]. Therefore, the search for effective treatment strategies for patients with MDR-TB has become a subject of intensive clinical research.

It has been reported that TB infection and prognosis may have a certain relationship with oxidative stress, leading to disorders in the balance between pro-oxidants and antioxidant system $[7,8]$. Quinolones have effects on MDRTB, which may be relevant with oxidative stress imbalance [9].

\section{METHODS}

\section{General information}

A total of 130 patients with MDR-TB treated in Eastern Medical District of Linyi People's Hospital of Shandong Province, from October 2014 to October 2016 were enrolled. The diagnostic criteria were in accordance with the Guidelines for the Diagnosis and Treatment of Tuberculosis (2013 version) [10] . Inclusion criteria were: patients aged 18 - 60 years; patients who were not taking quinolone antibiotics (including hypnathic acid, pipemidic acid, norfloxacin and gatifloxacin) at least 90 days before enrollment; patients free from cardiovascular disease history (including coronary heart disease and myocardial infarction); absence of significant ECG abnormalities like QRS wide malformations and QT interval prolonged; and absence of neuropsychiatric history like bipolar disorder and schizophrenia.

Exclusion criteria patients with autoimmune diseases; long-term use of immunosuppressive agents; bacteria or fungal infectious diseases like Streptococcus pneumonia and large area of yellow ringworm. The ethics committee of hospital approved the study (approval No. LY2014050) whih also followed the guidelines of Declaration of Helsinki, as amended in 1996 [11], and all patients were informed. All the patients of this study gave their informed consent, and were randomly divided into observation group (65 cases) and control group (65 cases). There was no significant difference between the two groups in with regard to their profiles, including gender, age, course of disease, smoking history, MDR-
TB clinical classification, and basic disease and laboratory tests $(p>0.05$, Table 1$)$.

The control group was treated with conventional drug regimen, amikacin, dipasic, rifapentine and ethambutol, abbreviated as $6 \mathrm{ADL}_{2} \mathrm{E} / 18 \mathrm{DL}_{2} \mathrm{E}$; where $A, D, L 2$ and $E$ refer to amikacin, dipasic, rifapentine and ethambutol, respectively, while the figures refer to 6 and 18 months. The observation group was treated with moxifloxacin (Bayer Healthcare Co., Ltd.), specifically $6 \mathrm{ADL}_{2} \mathrm{EM} / 18 \mathrm{DL}_{2} \mathrm{EM}$, where $M$ refers to moxifloxacin. During the treatment, regular blood routine examination, liver function and kidney function were carried out.

\section{Determination of TAS, TOS, OSI and PON-1 in serum}

The xylenol orange method was used to determine the total oxidant status (TOS) by using an automatic biochemical analyzer (HITACHI, Japan). In this method, ferrous ion $\left(\mathrm{Fe}^{2+}\right)$ is oxidized to ferric ions $\left(\mathrm{Fe}^{3+}\right)$, which react with xylenol orange. The color intensity is proportional to TOS level, expressed as $\mu \mathrm{mol} \mathrm{H}_{2} \mathrm{O}_{2}$ Equiv/L.

Total antioxidant status (TAS) was measured by the ABTS method using automatic biochemical analyzer (HITACHI, Japan). The total antioxidants reacted with ABTS (2, 2'-amino-di-3ethyl-benzothiazolinesulfonic acid-6 ammonium salt). TAS level, which was expressed as mmol Trolox Equiv/ $L$ is proportional to the magnitude of color change seen in the reaction. Oxidative Stress Index (OSI) was obtained as in Eq 1.

$O S I=\{(T O S) /(T A S \times 1000)\} 100$.

For serum PON-1 activity, venous blood samples (4\%) was drawn after $8 \mathrm{~h}$ fast and centrifuged at $3000 \mathrm{r} / \mathrm{min}$ at $4{ }^{\circ} \mathrm{C}$ for $10 \mathrm{~min}$ to collect the supernatant. PONI-1 was assayed by spectrophotometry (SP). Activity was calculated as in Eq 2 [12].

$P O N 1$ activity $(k u / L)=\{A \times F \times F V /(t \times S V \times L \times \varepsilon)\} 10^{3} \ldots$

where $A$ is the net absorbance value (i.e. the absorbance value of the specimen minus the absorbance value of the serum control and the substrate control); $F$ is the dilution factor of the specimen, $F V$ is the final volume of the reaction, $t$ is the reaction time ( $\mathrm{min}), S V$ is the sample volume $(L), L$ is the optical path $(\mathrm{cm})$, and $\varepsilon$ is the molar extinction coefficient. One unit of pon-1 activity was defined as $1 \mu$ enzyme required to catalyze the hydrolysis of $1 \mu \mathrm{mol}$ phenylacetate per minute. 


\section{Criteria for determination of efficacy}

Bacteriological evaluation or X-ray examination was used for efficacy determination. If sputum examination (3 consecutive sputum smears and 1 sputum TB) showed negative results or decreased amounts of inoculum, the treatment was effective, but if it was unchanged or if the amount of inoculum was increased, the treatment was ineffective. X-ray evaluation results were deemed to indicate effective treatment if the lesions were resolved, while deterioration of lesions or absence of significant changes in lesions indicated ineffective treatment [13].

\section{Statistical analysis}

All the data in this study were analyzed by SPSS 22.0 Statistical Software. Measurement data of normal distribution are expressed as mean \pm SD, and t-test or analysis of variance (ANOVA) was used for group comparison. Enumeration data are presented as $\{n(\%)\}$, and analyzed by Chisquare test. Pearson or Spearman correlation analysis was employed for correlation analysis, while $p<0.05$ was considered statistically significant.

\section{RESULTS}

\section{General information of the two groups}

There were no significant differences in gender, age, duration of disease, smoking history and other general data $(p>0.05)$. The prevalence of hematogenous disseminated TB, infiltrative pulmonary TB, chronic fibrous $T B$ and $T B$ pleurisy were no significant differences $(p>$ 0.05). In addition, the proportion of patients with chronic bronchitis and diabetes showed no significant difference $(p>0.05)$, the estimated values of albumin, neutrophils, white blood cell, alanine aminotransferase and serum creatinine had no significant differences ( $p>0.05$, Table 1$)$.

\section{Changes in serum TAS, TOS, OSI and PON1 levels in both groups before and after treatment}

There were no significant differences in TOS, OSI and PON1 levels of two groups before treatment $(p>0.05)$. In the observation group, the levels of TOS and OSI were significantly lower than those in the control group, while TAS and PON1 were significantly higher than those in the control group $(p<0.05)$. The levels of TOS and OSI in the observation group were significantly decreased, while the levels of TAS and PON1 were significantly increased after treatment $(p<0.05)$. When compared with those before treatment, the levels of TOS and OSI lowered significantly after treatment in control group $(p<0.05)$ while changes in TAS and PON1 had no statistically significant $(p>0.05$, Table 2).

\section{Correlation analysis}

In the correlation analysis between smoking history/diabetes/moxifloxacin/chronic bronchitis/moxifloxacin and TAS/TOS/OSI/PON1 levels $\{\Delta=$ (after treatment - before treatment) $\}$, moxifloxacin was positively in correlation with $\triangle$ TAS $(r=0.697, p=0.04)$ and $\triangle$ PON1 $(r=$ $0.785, p=0.01$ ), but negatively correlated with $\triangle \operatorname{TOS}(r=-0.625, p=0.01)$. There were no significant differences among the other indices $(p$ $>0.05$, Table 3).

Table 1: Demographic and general profile $\{($ mean \pm SD), $n(\%)\}$

\begin{tabular}{|c|c|c|c|c|}
\hline Variable & $\begin{array}{c}\text { Observation group } \\
(65)\end{array}$ & Control group (65) & $t$ or $x^{2}$ & $p$-value \\
\hline Gender (M/F) & $37 / 28$ & $42 / 23$ & 0.81 & 0.37 \\
\hline Age & $50.2 \pm 4.7$ & $51.1 \pm 3.9$ & 1.19 & 0.24 \\
\hline Duration of disease (year) & $12.2 \pm 4.8$ & $11.9 \pm 4.4$ & 0.37 & 0.71 \\
\hline Smoking history & $19(29.23 \%)$ & $17(26.15 \%)$ & 0.15 & 0.70 \\
\hline Hematogenous disseminated TB & $26(40.00 \%)$ & $29(44.61 \%)$ & 0.28 & 0.59 \\
\hline Infiltrative pulmonary TB & $17(26.15 \%)$ & $14(21.54 \%)$ & 0.38 & 0.54 \\
\hline Chronic fibrous TB & $8(12.31 \%)$ & $11(16.92 \%)$ & 0.56 & 0.46 \\
\hline TB pleurisy & $14(21.54 \%)$ & $11(16.92 \%)$ & 0.44 & 0.50 \\
\hline Diabetes & $17(26.15 \%)$ & $20(30.77 \%)$ & 0.34 & 0.56 \\
\hline Chronic bronchitis & $7(10.77 \%)$ & $5(7.69 \%)$ & 0.37 & 0.55 \\
\hline Albumin (g/L) & $29.9 \pm 3.1$ & $30.5 \pm 2.8$ & 1.16 & 0.25 \\
\hline White blood cell $\left(10^{9} / \mathrm{L}\right)$ & $7.67 \pm 1.24$ & $7.49 \pm 1.33$ & 0.80 & 0.43 \\
\hline Serum creatinine (umol/L) & $77.1 \pm 10.4$ & $74.6 \pm 12.5$ & 1.24 & 0.22 \\
\hline
\end{tabular}


Table 2: Changes of serum TAS, TOS, OSI and PON1 levels in both groups before and after treatment (mean \pm SD)

\begin{tabular}{|c|c|c|c|c|c|}
\hline Parameter & & $\begin{array}{c}\text { Observation } \\
\text { group (65) }\end{array}$ & $\begin{array}{c}\text { Control group } \\
(65)\end{array}$ & $t$ or $x^{2}$ & $p$-value \\
\hline \multicolumn{6}{|l|}{ TAS (umol Trolox Eq/L) } \\
\hline & Before & $1.4 \pm 0.5$ & $1.6 \pm 0.3$ & 2.77 & 0.28 \\
\hline & After & $3.5 \pm 0.7^{\pi}$ & $2.0 \pm 0.6$ & 13.12 & 0.00 \\
\hline \multicolumn{6}{|l|}{ TOS (umol $\mathrm{H}_{2} \mathrm{O}_{2} \mathrm{Eq} / \mathrm{L}$ ) } \\
\hline & Before & $23.3 \pm 4.7$ & $23.6 \pm 4.4$ & 0.38 & 0.71 \\
\hline & After & $13.9 \pm 3.3^{x}$ & $17.5 \pm 4.6$ & 5.13 & 0.00 \\
\hline \multicolumn{6}{|l|}{ OSI (U) } \\
\hline & Before & $17.4 \pm 4.8$ & $16.9 \pm 5.5$ & 0.55 & 0.58 \\
\hline & After & $5.7 \pm 1.4$ & $7.4 \pm 3.2$ & 3.92 & 0.01 \\
\hline \multicolumn{6}{|l|}{ PON1 (U/L) } \\
\hline & Before & $15.5 \pm 6.9$ & $16.1 \pm 4.4$ & 0.59 & 0.57 \\
\hline & After & $31.1 \pm 8.3^{\pi}$ & $19.9 \pm 7.4$ & 8.12 & 0.00 \\
\hline
\end{tabular}

Note: Compared to pre- treatment, $p<0.05$.

Table 3: Correlation analysis results

\begin{tabular}{|c|c|c|c|c|c|c|c|c|}
\hline \multirow[b]{2}{*}{ Variable } & \multicolumn{2}{|c|}{$\triangle \mathrm{TAS}$} & \multicolumn{2}{|c|}{$\triangle \mathrm{TOS}$} & \multicolumn{2}{|c|}{$\triangle \mathrm{OSI}$} & \multicolumn{2}{|c|}{$\triangle$ PON1 } \\
\hline & $r$ & $\begin{array}{c}p- \\
\text { value }\end{array}$ & $r$ & $\begin{array}{c}p- \\
\text { value }\end{array}$ & $r$ & $\begin{array}{c}p- \\
\text { value }\end{array}$ & $r$ & $\begin{array}{c}p- \\
\text { value }\end{array}$ \\
\hline Smoking history & 0.01 & 0.66 & -0.01 & 0.69 & -0.02 & 0.55 & -0.03 & 0.55 \\
\hline Diabetes & -0.04 & 0.33 & -0.03 & 0.049 & 0.04 & 0.26 & -0.02 & 0.59 \\
\hline Chronic bronchitis & 0.01 & 0.61 & 0.06 & 0.14 & -0.01 & 0.68 & -0.02 & 0.50 \\
\hline Moxifloxacin & 0.70 & 0.04 & -0.63 & 0.01 & 0.23 & 0.09 & 0.79 & 0.01 \\
\hline$\triangle \mathrm{TAS}$ & - & - & -0.12 & 0.11 & -0.02 & 0.19 & 0.24 & 0.11 \\
\hline$\triangle \mathrm{TOS}$ & -0.11 & 0.15 & - & - & -0.04 & 0.35 & -0.19 & 0.07 \\
\hline$\Delta \mathrm{OSI}$ & -0.02 & 0.18 & -0.05 & 0.30 & - & - & 0.01 & 0.41 \\
\hline$\triangle \mathrm{PON} 1$ & 0.25 & 0.19 & -0.19 & 0.09 & 0.06 & 0.41 & - & - \\
\hline
\end{tabular}

Comparison of effectiveness of treatment between the two groups

The treatment efficacy was significantly higher in the observation group than that in the control group $(p<0.05$, Table 4$)$.

Table 4: Effective rate of treatment for the two groups \{n (\%)\}

\begin{tabular}{lcc}
\hline Group & Effective & Ineffective \\
\hline $\begin{array}{l}\text { Observation group } \\
(\mathrm{n}=65)\end{array}$ & $53(81.54)$ & $12(18.46)$ \\
Control group $(\mathrm{n}=$ & $37(56.92)$ & $28(43.08)$ \\
$65)$ & & 9.24 \\
$X^{2}$ & & 0.00 \\
$P$-value & \\
\hline
\end{tabular}

\section{DISCUSSION}

Studies have shown that Mycobacterium tuberculosis gene mutations could occur in the process of growth and reproduction to form resistant strains due to environmental factors. The emergence of clinically resistant strains is closely linked to factors such as insufficient drug dosage, improper medication methods, inadequate course of treatment or intermittent medication and inappropriate order of medication. These factors cause resistance to first-line drugs (isoniazid, rifampicin and pyrazinamide), and second-line drugs (injectables, fluoroquinolones and antiinflammatory drugs). In MDR-TB, alveolar macrophages and other anti-inflammatory cells accumulate, engulfing MDR-TB bacteria and releasing a large number of reactive oxygen species (ROS), which result in local inflammatory response and damage $[14,15]$.

Quinolones, also known as pyridine carboxylic acids or pyridine acids, are synthetic 4-quinolone antibacterial drugs. Quinolones are targeted at DNA, thereby blocking DNA gyrase and further causing irreversible damage to DNA. Compared with the first 3 generations of quinolone antibiotics, moxifloxacin as a fourth-generation quinolone accumulates highly in respiratory mucosa, lung tissue, bronchoalveolar lavage fluid and macrophages, effectively killing lung TB mycobacteria $[16,17]$. In this study, moxifloxacin treatment was used in the observation group, and it greatly improved the effectiveness of MDR-TB. During infections, trauma, and poisoning, large amounts of inflammatory substances are generated, leading to imbalance in antioxidant system known as oxidative stress $[9,18]$. In MDR-TB patients, excessive activation and aggregation of macrophages and neutrophils 
occur, with resultant imbalance between oxidant and antioxidant system, which accounts for high oxidative stress [19]. In this study, total oxidant status and antioxidant status gradually recovered in the two groups of patients after treatment: TAS and PON1 levels significantly increased, while TOS and OSI levels decreased. The degree of improvement was more pronounced in patients with moxifloxacin combination therapy.

Malnutrition is one of the most important causes of high oxidative stress in TB patients. Poor appetite and inadequate intake of vitamin $C$ and other antioxidants by MDR-TB patients may also lead to oxidative stress injury [20]. However, in this study, the albumin levels in the two groups of patients were within normal range, and their difference was not statistically significant. PON1 is a calcium-sensitive lipase with the physiological function of hydrolyzing lipid peroxides in vivo. The activity of PON1 is significantly reduced in oxidative stress conditions [21]. In this study, PON1 activity was significantly decreased in both groups before treatment, and increased after treatment, with more significant increase in the observation group. In the correlation analysis, moxifloxacin had a positive correlation with PON1 activity, and its mechanism of action might be related to mitigation of Mycobacterium tuberculosismediated chronic oxidative stress injury $[22,23]$.

\section{Limitations of the study}

However, this study is a controlled study using a small sample, and the specific mechanism of action of moxifloacin is yet to be elucidated. Thus, further, well-designed studies based on multiple centers are needed in this respect.

\section{CONCLUSION}

The results of this study indicate that moxifloxacin can improve the imbalance in oxidant-antioxidant system in patients with MDR$\mathrm{TB}$, reduce the associated high oxidative stress, and improve the efficiency of treatment.

\section{DECLARATIONS}

\section{Acknowledgement}

None.

\section{Conflict of Interest}

No conflict of interest associated with this work.

\section{Contribution of Authors}

The authors declare that this work was done by the authors named in this article and all liabilities pertaining to claims relating to the content of this article will be borne by them.

\section{Open Access}

This is an Open Access article that uses a funding model which does not charge readers or their institutions for access and distributed under the terms of the Creative Commons Attribution License (http://creativecommons.org/licenses/by/ 4.0) and the Budapest Open Access Initiative (http://www.budapestopenaccessinitiative.org/rea d), which permit unrestricted use, distribution, and reproduction in any medium, provided the original work is properly credited.

\section{REFERENCES}

1. Pai M, Correa N, Mistry N, Jha P. Reducing global tuberculosis deaths-time for India to step up. Lancet 2017; 389(10075): 1174-1176.

2. Walker TM, Cruz AL, Peto TE, Smith EG, Esmail $H$, Crook DW. Tuberculosis is changing. Lancet Infect Dis 2017; 17(4): 359-361.

3. Shi T, Zhang Z, Dai F, Zhou Q, He Q, Luo F, Hou T, Xu J. Retrospective Study of 967 Patients With Spinal Tuberculosis. Orthopedics 2016; 39(5): e838-843.

4. Gómezayerbe C, Vivancos MJ, Moreno S. Multidrugresistant tuberculosis: current epidemiology, therapeutic regimens, new drugs. Rev Esp Quimioter 2016; 29 Suppl 1(11): 35-38.

5. Liu BB, Pei-Lei HU, Gong DF, Song-Lin YI, Liu FP, Tan $Y H$. Profile and influencing factors of drug resistance of Mycobacterium tuberculosis in smear-positive pulmonary tuberculosis patients in Hunan Province. Chin J Infec Control 2016,02(15): 73-78.

6. Ge $Q, D u J$, Jiang $G$, et al. Comparative study on the treatment effect of standard retreatment regimen in patients with poly-drug resistant and drug sensitive pulmonary tuberculosis. Chin J Antitubercul 2015; 37(8): 879-884.

7. Batra J, Arora VK. Oxidative stress and tuberculosis. Indian J Tuberc 2014; 61(3): 183-185.

8. Wittwer $M$, Luo $Q$, Kaila VR, Dames SA. Oxidative Unfolding of the Rubredoxin Domain and the Natively Disordered N-terminal Region Regulate the Catalytic Activity of M. tuberculosis Protein Kinase G. Journal of Biological Chemistry 2016; 291(53): 27062-27072.

9. Yang HS, Xi-Rong XU, Shen Q, Jin Y, Hospital SC. Effect of moxifloxacin on serum levels of PON1 and oxidative markers in patients with multiple drug resistant tuberculosis. J Clini Pulmonary Med 2016; 21(4): 606608. 
10. Li L, XU S. Current situation and prospect on tuberculosis diagnosis and treatment in China. Chin $J$ Prac Intern Med 2015; 35(8): 643-646.

11. World Health Organization. Declaration of Helsinki. $\mathrm{Br}$ Med J 1996; 313(7070): 1448-1449.

12. Sampson MJ, Braschi S, Willis G, et al. Paraoxonase-1 (PON-1) genotype and activity and in vivo oxidized plasma low-density lipoprotein in Type II diabetes[J]. Clin Sci, 2005;109(2):189-197.

13. Luo P, Tu D, Hong F, Wang J, Wang S, Zhang T. Effect analysis on standard regimens of retreatment pulmonary tuberculosis in 177 cases. Chin J Antitubercul 2013; 35(5): 347-351.

14. Chen $Y$, Zhao L. Drug resistance associated mutations in multi-drug resistant Mycobacterium tuberculosis. Dis Surveill 2014; 29(4): 305-309.

15. Islam MM, Hameed HM, Mugweru J, Chhotaray C, Wang C, Tan Y, Liu J, Li X, Tan S, Ojima I. Drug resistance mechanisms and novel drug targets for tuberculosis therapy. J Genet Genomics 2016; 44(1): 21-37.

16. Kang YA, Shim TS, Koh WJ, Lee SH, Lee CH, Choi JC, Lee $\mathrm{JH}$, Jang $\mathrm{SH}$, Yoo KH, Jung $\mathrm{KH}$. Choice between Levofloxacin and Moxifloxacin and Multidrug-Resistant Tuberculosis Treatment Outcomes. Ann Am Thorac Soc 2016; 13(3): 186-191.

17. López-Gavín A, Tudó G, Vergara A, Hurtado JC, Gonzalez-Martín J. In vitro activity against Mycobacterium tuberculosis of levofloxacin, moxifloxacin and UB-8902 in combination with clofazimine and pretomanid. Int $J$ Antimicrob Agents 2015; 46(5): 582-585.

18. Lin J. The influence of moxifloxacin on serum levels of PCT and STREM-1 in patients with multiple drug resistance tuberculosis. Lab Med Clin 2016; 13(22):3138-3140.

19. Webster D, Long R, Shandro C, Pettipas J, Leblanc J, Davidson R, Fanning A. Fluoroquinolone resistance in renal isolates of Mycobacterium tuberculosis. Int $\mathrm{J}$ Tuberc Lung Dis 2010; 14(2): 217-222.

20. Wang $Y K$, Han $X X$, Wang QZ, Ai-Guo MA, Zhao SL, Zhao J, Wang YW. Dietary Diversity Score and Nutrient Intakes of Tuberculosis Patients. Food Nutr China 2011;17(1): 73-77.

21. Torun E, Gedik AH, Cakir E, Umutoglu T, Gok O, Kilic U. Serum paraoxonase 1 activity and oxidative stress in pediatric patients with pulmonary tuberculosis. Medi Princ Pract 2014; 23(5): 426-431.

22. Brinholi FF, Noto $C$, Maes $M$, Bonifácio KL, Brietzke $E$, Ota VK, Gadelha A, Cordeiro Q, Belangero SI, Bressan $R A$. Lowered paraoxonase 1 (PON1) activity is associated with increased cytokine levels in drug naive first episode psychosis. Schizophr Res 2015; 166(1-3): 225-230.

23. Gillespie SH. The role of moxifloxacin in tuberculosis therapy. Eur Respir Rev 2016; 25(139): 19-28. 